\title{
Prophylactic Effect of Polaprezinc, a Zinc-L-carnosine, Against Chemotherapy-induced Oral Mucositis in Pediatric Patients Undergoing Autologous Stem Cell Transplantation
}

\author{
MIYUI FUNATO ${ }^{1}$, MICHIO OZEKI ${ }^{2}$, AKIO SUZUKI ${ }^{1}$, MASASHI ISHIHARA ${ }^{1}$, RYO KOBAYASHI $^{1}$, \\ AKIFUMI NOZAWA ${ }^{2}$, SHIHO YASUE ${ }^{2}$, SAORI ENDO-OHNISHI ${ }^{2}$, TOSHIYUKI FUKAO ${ }^{2}$ and YOSHINORI ITOH ${ }^{1}$ \\ ${ }^{1}$ Department of Pharmacy, Gifu University Hospital, Gifu, Japan; \\ ${ }^{2}$ Department of Pediatrics, Gifu University Graduate School of Medicine, Gifu, Japan
}

\begin{abstract}
Background/Aim: Polaprezinc suspension in sodium alginate ( $P Z-A G)$ reduces the incidence and severity of oral mucositis in adult patients receiving radiotherapy or high-dose chemotherapy. In the present study, the prophylactic effect of PZ-AG against oral mucositis was assessed in pediatric patients with hematological malignancies receiving high-dose chemotherapy followed by hematopoietic stem cell transplantation (HSCT). Patients and Methods: Data of 16 children who underwent HSCT during a period between January 2010 and December 2017 were obtained from medical records and they were retrospectively analyzed. Oral mucositis was evaluated by the WHO scale. Results: Six (37.5\%) of 16 children refused to take PZ-AG in a preliminary assessment and they were pretreated with azulene gargle. The remaining 10 (62.5\%) patients were pretreated with PZ-AG for prevention of oral mucositis. Grade $\geq 3$ oral mucositis occurred in 5 (83.3\%) of 6 patients receiving azulene gargle, but in $2(20 \%)$ patients who took PZ-AG ( $p=0.035)$. The prevalence for the use of opioid analgesics was also significantly lower $(30 \%$ vs. $100 \%, p=0.011)$, while the average duration of total parenteral nutrition use was significantly shorter (11.1 days vs. 24.3 days, $p=0.016)$, in PZ-AG group than in azulene group. On the other hand, PZ-AG had no significant influence on the incidence of other adverse events, mean time to engraftment, or overall survival. Conclusion: PZ-AG was found to be highly effective in preventing oral mucositis
\end{abstract}

This article is freely accessible online.

Correspondence to: Akio Suzuki, Department of Pharmacy, Gifu University Hospital, 1-1 Yanagido, Gifu 501-1194, Japan. Tel: +81 582306000, e-mail: akio@gifu-u.ac.jp

Key Words: Oral mucositis, polaprezinc, chemotherapy, hematopoietic stem cell transplantation. in pediatric patients with hematological malignancies receiving high-dose chemotherapy followed by HSCT, as in adult patients.

Oral mucositis is one of the most common and distressful complications in cancer chemotherapy and/or radiotherapy and is often accompanied by pain, odynophagia, dysgeusia and subsequent dehydration and malnutrition, which reduces patients' quality of life (QOL) $(1,2)$. Especially, the incidence of oral mucositis in pediatric and adolescent patients is about three times higher than that in adult patients because of a higher proliferation rate of basal cells (3). Additionally, children who receive high-dose chemotherapy followed by hematopoietic stem cell transplantation (HSCT) are at high risk of developing severe oral mucositis $(4,5)$. Cheng et al. reported in a multicenter study consisting of 140 patients with ages between 6 and 18 years old that highsymptom burden due to oral mucositis induced by cancer chemotherapy may have profound impacts on patient QOL and levels of psychological burdens on patients and their families (6). Therefore, the prevention or amelioration of oral mucositis associated with chemotherapy and/or radiotherapy is important in children.

Palifermin (Kepivance, Swedish Orphan Biovitrum AB, Stockholm, Sweden), which is a recombinant human keratinocyte growth factor (KGF), decreases the severity and duration of oral mucositis after intensive therapy for hematologic cancers in adult patients $(7,8)$. In children receiving HSCT conditioning using high-dose chemotherapy associated with a high rate of severe oral mucositis, KGF was recommended as only a prophylactic agent against oral mucositis by the Pediatric Oncology Group of Ontario (POGO) Mucositis Prevention Guideline Development Group (9). However, the recommendation for the use of KGF in pediatric patients is weak, because of the lack of sufficient data on the efficacy and toxicity and long-term follow-up of KGF (9). Therefore, the development of a prophylactic agent 
for oral mucositis associated with cancer treatment in pediatric cancers remains a significant challenge world-wide.

We recently reported that oral ingestion of polaprezinc, a zinc-L-carnosine, suspension in sodium alginate (PZ-AG) is highly effective for prevention of oral mucositis associated with radiotherapy in adult patients with head and neck cancer, as well as in adult patients with high-dose chemotherapy for HSCT (10-12). This compound is highly safe and approved in Japan as an anti-ulcerative drug with mucoprotective action. However, it is still unclear whether PZ-AG prevents the incidence of oral mucositis induced by chemotherapy in children with high-dose chemotherapy for HSCT. The present study was designed to clarify the prophylactic effect of PZ-AG against oral mucositis in children with hematological malignancies receiving highdose chemotherapy followed by HSCT.

\section{Patients and Methods}

Study design and patients. Data obtained from medical records were analyzed retrospectively. Sixteen children with hematological malignancies, ranging from 1 year to 18 years in age, breceived high-dose chemotherapy followed by autologous peripheral blood stem cell transplantation during a period from January 2010 to December 2016. We preliminary checked whether PZ-AG could be acceptable to the children before introduction of chemotherapy. In patients who could not take PZ-AG, azulene gargle was pretreated for prevention of oral mucositis.

Preparation of polaprezinc sodium alginate suspension (PZ-AG). Polaprezinc (Promac granules VR 15\% ${ }^{\circledR}$, Zeria Pharmaceutical Co., Tokyo, Japan) at $0.5 \mathrm{~g}$ was suspended in $20 \mathrm{ml}$ of $5 \%$ sodium alginate solution. Five ml volume of PZ-AG suspension was orally rinsed for $2 \mathrm{~min}$, then swallowed for 4 times in a day and continued for a month after transplantation. PZ-AG was started to be administered before introduction of chemotherapy.

Evaluation of oral mucositis and other adverse events. The incidence and severity of oral mucositis was evaluated according to the World Health Organization (WHO) oral mucositis grading scale, as follows: no symptom of oral mucositis (grade 0), oral soreness or erythema was observed (grade 1), oral erythema and ulcers or the patients can eat solids (grade 2), oral ulcers or the patients can take liquid diet only (grade 3) and the oral nourishment is not possible (grade 4) (13).

The incidence rates and severity of rash, erythema, nausea, vomiting and diarrhea were evaluated according to the Common Terminology Criteria for Adverse Events (CTCAE, National Cancer Institute, MD, USA) version 4.0. The prevalence for the use of analgesics, including local anesthetics and opioid analgesics, for the relief of pain associated with oral mucositis was compared between azulene group and PZ-AG group.

Ethics statement. The present study was conducted according to the guidelines for human studies determined by the ethics committee of Gifu University Graduate School of Medicine and the Government of Japan and was approved by the institutional review board (approval no. 23-145). In view of the retrospective nature of the study, the need for the informed consent of subjects was not mandated.
Table I. Patient demographics.

\begin{tabular}{lccc}
\hline & Azulene & PZ-AG & $p$-Value \\
\hline Gender (male/female) & $4 / 2$ & $5 / 5$ & $0.632^{\mathrm{a}}$ \\
Age (mean, range) & $8.8(1-5)$ & $7.2(2-18)$ & $0.891^{\mathrm{b}}$ \\
Hight (cm) & $128.8 \pm 38.5$ & $112.1 \pm 0.35$ & $0.212^{\mathrm{c}}$ \\
Weight (kg) & $33.1 \pm 19.3$ & $21.5 \pm 12.7$ & $0.167^{\mathrm{c}}$ \\
Body surface area (m $\left.{ }^{2}\right)$ & $1.10 \pm 0.48$ & $0.80 \pm 0.35$ & $0.212^{\mathrm{c}}$ \\
Serum albumin $(\mathrm{g} / \mathrm{dl})$ & $4.1 \pm 0.18$ & $4.1 \pm 0.24$ & $0.977^{\mathrm{c}}$ \\
Aspartate aminotransferase (u/l) & $31.3 \pm 9.75$ & $32.3 \pm 13.7$ & $0.883^{\mathrm{c}}$ \\
Alanine aminotransferase (u/l) & $36.5 \pm 36.6$ & $25.5 \pm 14.5$ & $0.405^{\mathrm{c}}$ \\
Serum creatinine (mg/dl) & $0.40 \pm 0.23$ & $0.30 \pm 0.28$ & $0.713^{\mathrm{c}}$ \\
White blood cells $\left(/ \mathrm{mm}^{3}\right)$ & $3737 \pm 5131.9$ & $3092 \pm 3103.2$ & $0.757^{\mathrm{c}}$ \\
Hemoglobin $(\mathrm{g} / \mathrm{dl})$ & $8.8 \pm 0.93$ & $9.7 \pm 0.73$ & $0.053^{\mathrm{c}}$ \\
Plate $\left(\times 10^{6} / \mathrm{mm}^{3}\right)$ & $19.2 \pm 5.35$ & $20.5 \pm 7.9$ & $0.733^{\mathrm{c}}$ \\
Diagnosis, \% & & & $0.977^{\mathrm{d}}$ \\
Neuroblastoma & $4(66.7)$ & $3(30)$ & \\
Medulloblastoma & $1(16.7)$ & $3(30)$ & \\
Ewing sarcoma & $1(16.7)$ & 0 & \\
Atomic neuroectodermal & 0 & $1(10)$ & \\
Rhabdomyosarcoma & 0 & $1(10)$ & \\
TumorVentricular ependymoma & 0 & $2(20)$ & \\
Chemotherapy regimens & & & $0.504^{\mathrm{d}}$ \\
CBDCA+L-PAM+ETP & $4(66.7)$ & $3(30)$ & \\
L-PAM + CPA & $1(16.7)$ & $6(60)$ & \\
BU + L-PAM & $1(16.7)$ & $1(10)$ & \\
\hline
\end{tabular}

aFisher's exact probability test, ${ }^{\mathrm{b}}$ Mann-Whitney $U$-test, ${ }^{\mathrm{c}} t$-test, ${ }^{\mathrm{d}}$ chisquare test. CBDCA: Carboplatin; L-PAM: Melphalan; ETP: etoposide; CPA: cyclophosphamide; BU: busulfex.

Statistical analysis. The parametric analysis was carried out by using $t$-test, while nonparametric analysis was performed by using Mann-Whitney $U$-test. The mean duration of engraftment was assessed by Kaplan-Meier method and was statistically compared between the two groups using the Mantel-Cox log-rank test.

Data were analyzed by using SPSS version 22 (SPSS Inc., Chicago, IL, USA) and GraphPad Prism version 6.0 (GraphPad Software, San Diego, CA, USA). The $p$-values of less than 0.05 were considered statistically significant.

\section{Results}

Comparison of patient demographics between PZ-AG group and azulene group. Of 16 eligible children, 6 (37.5\%) refused taking PZ-AG because of unfavorable taste and undesirable texture of PZ-AG in preliminary evaluation, and they were therefore pretreated with azulene gargle for prevention of oral mucositis (azulene group). Thus, the other 10 children (62.5\%) were pretreated with PZ-AG for prevention of oral mucositis induced by high-dose chemotherapy (PZ-AG group). Thereafter, the prophylactic effect of oral mucositis between azulene group and PZ-AG group was compared.

As shown in Table I, there were no significant differences in demographics, including gender, age, height, body weight, laboratory data, diagnosis and chemotherapy regimens between the two groups. The most common type of cancer was 
(A)

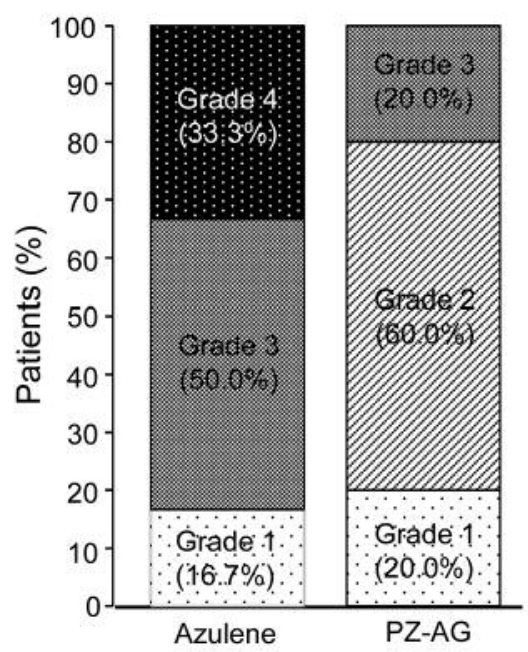

(B)

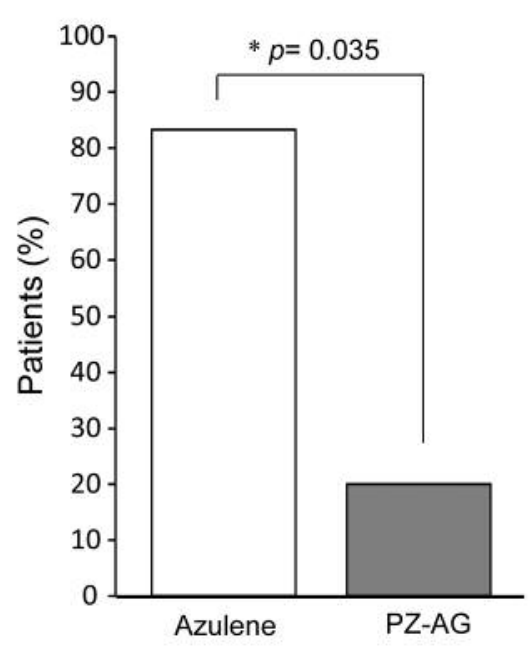

(C)

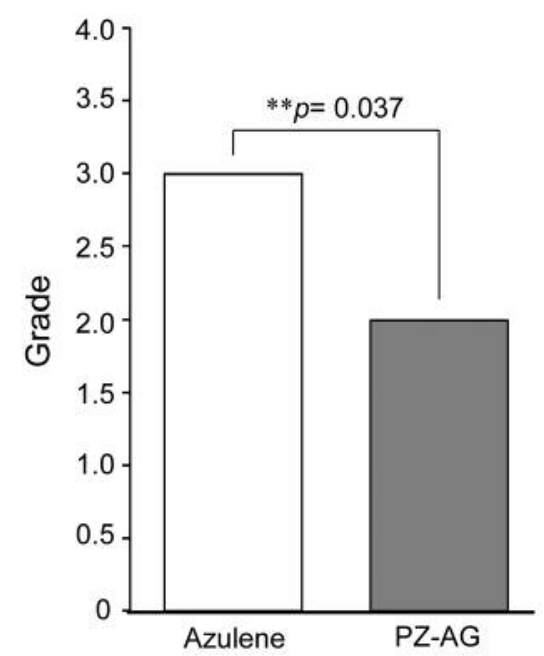

Figure 1. The incidence of (A) all four grade oral mucositis, (B) incidence of grade $\geq 3$ oral mucositis and (C) the severity of oral mucositis in patients receiving high dose chemotherapy and radiotherapy followed by HSCT between azulene group and PZ-AG group. *Fisher's exact probability test, **Mann-Whitney U-test.

neuroblastoma $(\mathrm{n}=4,66.7 \%)$, followed by medulloblastoma $(n=1,16.7 \%)$ and eEwing sarcoma $(n=1,16.7 \%)$ in azulene group, while neuroblastoma $(n=3,30 \%)$ and medulloblastoma $(\mathrm{n}=3,30 \%)$, followed by tumor ventricular ependymoma $(\mathrm{n}=2$, $20 \%)$, atomic neuroectodermal $(n=1,10 \%)$ and rhabdomyosarcoma $(n=1,10 \%)$ in PZ-AG group. The most common chemotherapy regimen was CBDCA + L-PAM + ETP (carboplatin, melphalan, etoposide) $(n=4,66.7 \%)$, followed by L-PAM + CPA (melphalan, cyclophosphamide) $(\mathrm{n}=1,16.7 \%)$ and BU + L-PAM (busulfex, melphalan) $(n=1,16.7 \%)$ in azulene group, and L-PAM + CPA $(n=6,60 \%)$, followed by CBDCA + L-PAM + ETP $(n=3,30 \%)$ and BU + L-PAM $(n=1$, $10 \%$ ) in PZ-AG group.

Incidence of oral mucositis, the prevalence of the use of analgesics and average period of total parenteral nutrition $(T P N)$. As shown in Figure 1A, the incidence rates of grade 1, grade 2 and grade 3 oral mucositis were $16.7 \%(1 / 6), 50 \%$ $(3 / 6)$ and $33.3 \%(2 / 6)$, respectively, in azulene group, but $20 \%$ $(2 / 10), 60 \%(6 / 10)$ and $20 \%(2 / 10)$, respectively, in PZ-AG group. The incidence of grade $\geq 3$ oral mucositis was significantly lower in PZ-AG group than in azulene group ( $20 \%$ vs. $83.3 \%, p=0.035$ ) (Figure 1B). Moreover, the average grade of oral mucositis was significantly lower in PZ-AG group than in azulene group (2.1 vs. 3.7, $p=0.037)$ (Figure 1C).

The prevalence for the use of opioid analgesics was significantly lower in PZ-AG group than in azulene group (30\% (3/10) vs. $100 \%(6 / 6), p=0.0113)$, although the prevalence for the use of non-opioid analgesics was not significantly different between the two groups (Figure 2A). Moreover, the average duration of TPN in PZ-AG group was significantly shorter than that in azulene group (11.1 days (95\% confidence interval $(\mathrm{CI})=0-32.7) v s .24 .3$ days $(15.3-34.0), p=0.016)$ (Figure 2B), while the implementation rate of TPN was slightly and not significantly lower in PZ-AG group than in azulene group (70\% for PZ-AG group vs. $100 \%$ for azulene group).

Comparison of the incidence rates of other nonhematological adverse events between the two groups. There were no significant differences in the incidence rates of other adverse events such as rash, malaise, nausea, vomiting and diarrhea between azulene group and PZ-AG group (Table II).

Comparison of the time to engraftment of HSCT and overall survival between the two groups. All patients in both azulene group and PZ-AG group succeeded in the engraftment. The mean time to engraftment tended to be shorter, though not significantly, in PZ-AG group than in azulene group (14.7 days $(95 \% \mathrm{CI}=9.9-25.8)$ vs. 17.2 days $(12.2-28.2), \mathrm{HR}=1.348$ (95\%CI=0.394-4.608), $p=0.634$ ) (Figure 3A). On the other hand, there was no significant difference in the rate of overall survival between the two groups $(\mathrm{HR}=0.9862$, 95\% CI=0.1652-5.877, $p=0.9877$ ) (Figure 3B).

\section{Discussion}

We previously reported that oral ingestion of PZ-AG was highly effective for prevention of oral mucositis associated with highdose chemotherapy for HSCT in adult patients with hematological malignancies (11). In the present study, the 
(A) Use of analgesics

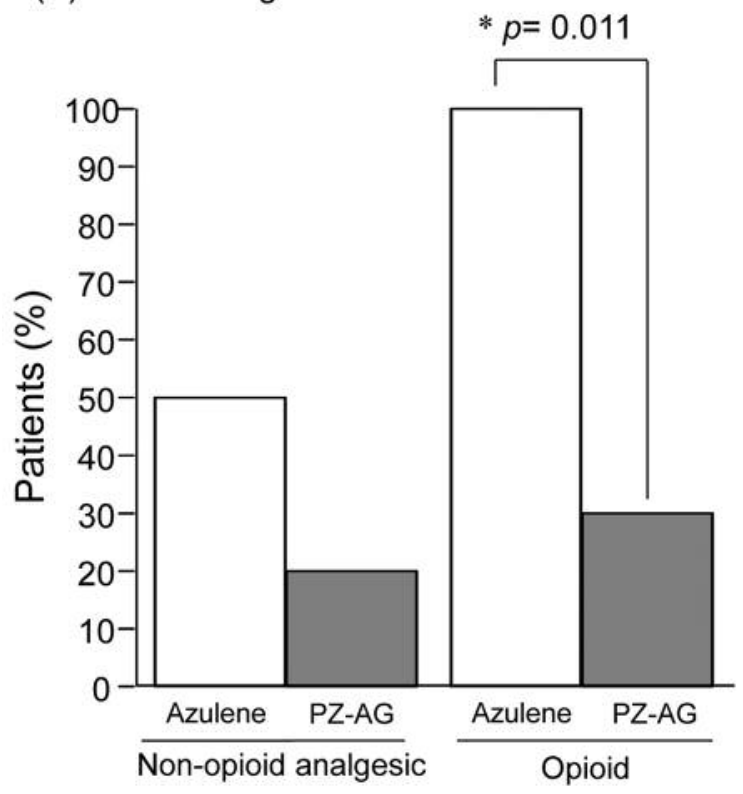

(B) Duration of TPN

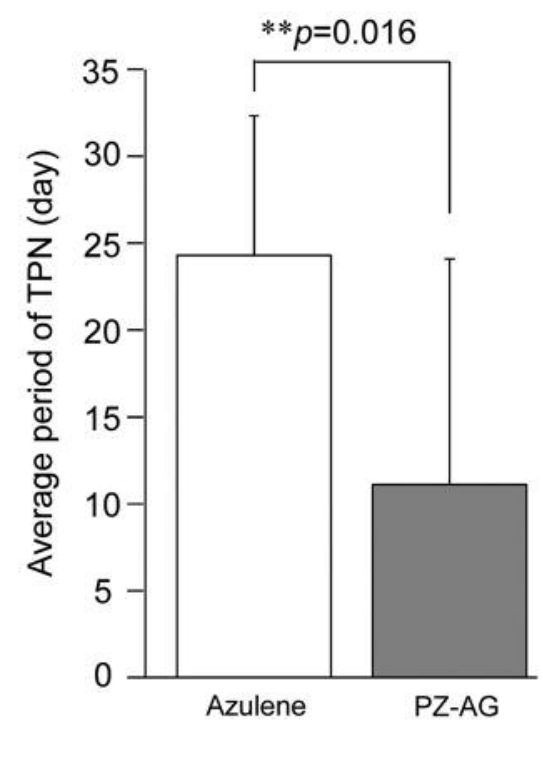

Figure 2. Comparison of the use of anesthetic agents and the average duration of TPN in patients receiving high dose chemotherapy and radiotherapy followed by HSCT between azulene group and PZ-AG group. *Fisher's exact probability test, **Mann-Whitney U-test.

prophylactic effect of PZ-AG was evaluated in pediatric patients (1-18 years old in age) with hematological malignancies who received high-dose chemotherapy followed by HSCT.

PZ-AG was effective in reducing the incidence of severe (grade $\geq 3$ ) oral mucositis and the severity (mean grade) of oral mucositis associated with high-dose chemotherapy for HSCT in children with hematological malignancy. As a consequence, the prevalence of the use of opioid analgesics was significantly lower in PZ-AG group than in azulene group. Moreover, the average duration of TPN use was significantly shorter in PZAG group than in azulene group. On the other hand, there were no significant differences in the incidence rates of other adverse events, including rash, malaise, nausea, vomiting and diarrhea. Moreover, PZ-AG had no significant influence on the clinical outcomes such as the rate of engraftment, time to engraftment, or the rate of overall survival. Taken together, it is suggested that PZ-AG is potentially useful for the selective prevention of oral mucositis in pediatric patients receiving high-dose chemotherapy for HSCT.

Zinc is generally considered to be relatively nontoxic in both pediatric and adult populations (14-16). Moreover, it is unlikely that zinc has mutagenic or carcinogenic action in human. Although a few studies have reported that advanced prostate cancer is associated with chronic intake of high amount of zinc $(17,18)$, a number of investigators have shown a lack of relationship between the intake of dietary or supplemental zinc and the development or progression of
Table II. Incidence of non-hematological adverse events.

\begin{tabular}{llcc}
\hline & Azulene & PZ-AG & $p$-Value \\
\hline Rash & 0 & $1(10 \%)$ & 1.000 \\
Malaise & $6(100 \%)$ & $10(100 \%)$ & 1.000 \\
Nausea & $6(100 \%)$ & $8(80 \%)$ & 0.500 \\
Vomiting & $6(100 \%)$ & $7(70 \%)$ & 0.250 \\
Diarrhea & $4(66 \%)$ & $5(55 \%)$ & 0.633 \\
\hline
\end{tabular}

Data were compared by chi-square test.

prostate cancer (19-21). Polaprezinc has long been used in Japan as anti-ulcer drug and proved to be highly safe. In the present study, the dose of polaprezinc was $75 \mathrm{mg}$ /day that was half of the dose used for anti-ulcer action. Moreover, PZ-AG was extremely inexpensive, in which the cost was JPY 59 (\$0.556)/day (JPY 1,796 (\$16.7)/month). Therefore, PZ-AG may become a potentially useful and highly cost-effective drug for prevention of oral mucositis induced in pediatric population by cancer chemotherapy.

However, oral acceptability of PZ-AG was limited since 6 of 16 patients $(37.5 \%)$ refused oral intake of this drug due to high viscosity of the insipid suspension, indicating that limitation of oral acceptability to children is a drawback of PZ-AG. Thus, it is necessary to develop a formulation that is 


\section{(A) Time to engraftment}

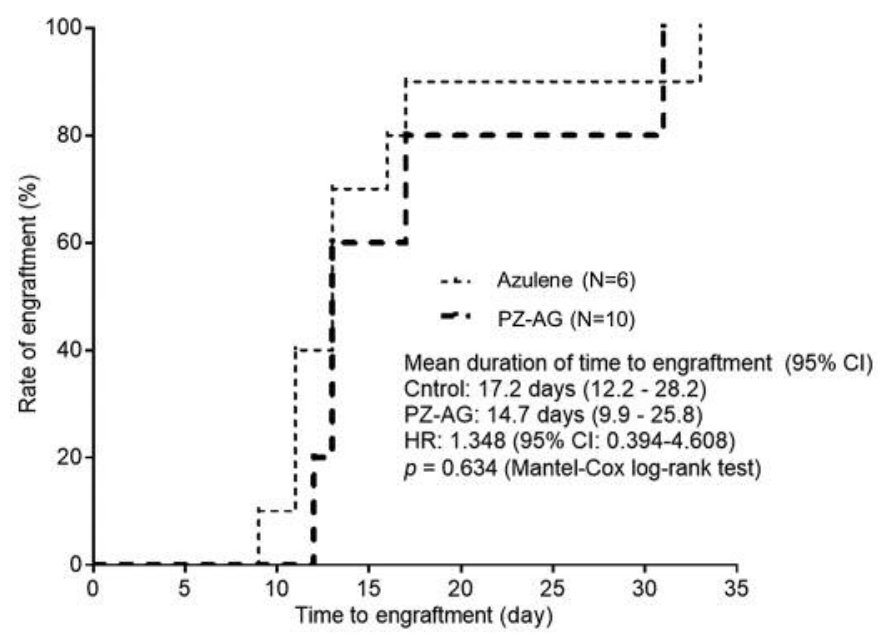

(B) Overall survival

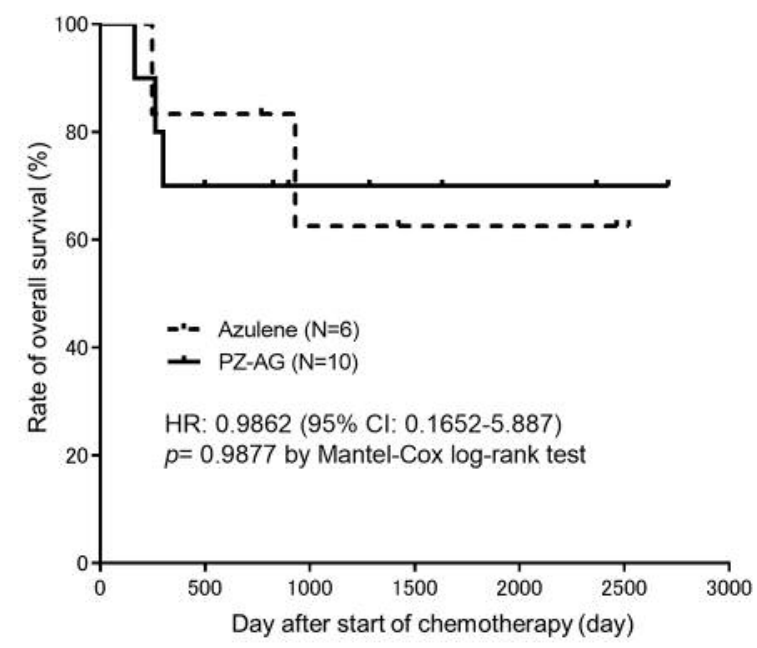

Figure 3. Kaplan-Meier plots showing (A) the time to engraftment and (B) overall survival after starting chemotherapy. Data were statistically compared using Mantel-Cox log rank test.

easy for children to take. We recently reported the preparation of a novel lozenge containing polaprezinc to resolve the problem of limited oral acceptability of PZ-AG (22).

The mechanisms underlying the prophylactic effect of polaprezinc against oral mucositis remain to be clarified. Polaprezinc is an insoluble zinc complex of L-carnosine. Zinc ion in polaprezinc may contribute to the protective action against oral mucositis induced by chemotherapy and/or radiotherapy. The Multinational Association of Supportive Care in Cancer and International Society of Oral Oncology Clinical Practice Guidelines provides a weak recommendation of oral administration of zinc supplements for prevention of oral mucositis in oral cancer patients receiving radiation therapy or chemotherapy (23). On the other hand, several investigators showed that polaprezinc inhibits the production of inflammatory cytokines, including tumor necrosis factor- $\alpha$, interleukin- $1 \beta$ and interleukin- 6 , all of which are considered to be involved in the pathogenesis of chemotherapy- or radiotherapy-induced oral mucositis (24-27). Therefore, in addition to the antioxidant effect of polaprezinc, the inhibitory of the production of inflammatory cytokines may contribute to the prophylactic action of polaprezinc against oral mucositis.

Although several agents, including KGF (28-31), granulocyte colony-stimulating factor (32-34), vitamin E (35), sucralfate (36), transforming growth factor- $\beta 2$-enriched feeding (37) and chlorhexidine gluconate (38) have been tested for prevention of oral mucositis associated with cancer treatment in pediatric patients, none of them except for KGF has been confirmed to show reproducible protective action. Lauritano et al. (31) showed in a case-control study of children undergoing allogeneic HSCT for acute lymphoblastic leukemia that KGF reduces the severity of mucositis (average grade: 1.73 for KGB vs. 2.47 for control, $p=0.030$ ), duration of parenteral nutrition (16 days vs. 26 days, $p=0.002$ ) and duration of mucositis (6 days vs. 12 days, $p=0.003$ ). Similarly, Czyzewski et al. (29) demonstrated by a matched-pair analysis in 62 pediatric patients undergoing first autologous HSCT that KGF significantly decreases the incidence of severe (grade 3-4 by WHO scale) oral mucositis, length of hospitalization, duration of oral mucositis $(p=0.035)$, and the incidence of clinically or microbiologically documented infections $(p=0.038)$. Vitale $e t$ al. (28) reported by a retrospective analysis in children undergoing autologous HSCT for malignant diseases that the incidence of grade 3-4 oral mucositis tends to decrease in KGF group as compared with in control group (20\% vs. $42.4 \%$, $p=0.072$ ). In addition, Lucchese et al. (30) reported in a randomized-controlled clinical trial in children with B-cell lineage acute lymphoblastic leukemia who received HSCT that KGF reveals a statistically significant reduction in the incidence of grade 3 and 4 oral mucositis as compared to placebo treatment. However, data concerning the safety and efficacy of KGF have not been sufficiently accumulated in pediatric population. Moreover, there has been a lack of longterm follow-up data on KGF regarding a possible incidence of secondary malignancies through the stimulation of KGF receptor in pediatric cancers $(9,39,40)$. Thus, the use of KGF is a weak recommendation, and KGF may be considered for children undergoing HSCT if the benefits of mucositis prevention outweigh the risks and costs (9). Moreover, KGF is highly expensive: one vial containing $6.25 \mathrm{mg}$ palifermin for injection is $\$ 1,650$ (data from Drugbank: https:// www.drugbank.ca/drugs/DB00039), and 6 injections (3 
consecutive days before and 3 consecutive days after chemotherapy) are required for prevention of oral mucositis.

There are several limitations in the present study. This was a retrospective study, thus several confounding factors could be ruled out. Second, sample size was small and data were obtained from a single institution. Therefore, a randomized control study in a larger scale is needed to demonstrate the prophylactic effect of PZ-AG against oral mucositis induced in pediatric patients by high dose chemotherapy followed by HSCT.

In conclusion, PZ-AG was found to be effective in reducing the incidence of severe oral mucositis in children with hematopoietic malignancies who received high dose chemotherapy followed by HSCT. PZ-AG is safe and inexpensive. Therefore, PZ-AG may become a highly costeffective agent that is potentially useful for prevention of oral mucositis associated with cancer chemotherapy in pediatric patients.

\section{Conflicts of Interest}

The Authors declare no conflict of interest for this research.

\section{Acknowledgements}

This work was supported by JSPS KAKENHI Grant Number JP $17 \mathrm{~K} 08440$.

\section{References}

1 McGuire DB, Altomonte V, Peterson DE, Wingard JR, Jones RJ and Grochow LB: Patterns of mucositis and pain in patients receiving preparative chemotherapy and bone marrow transplantation. Oncol Nurs Forum 20: 1493-1502, 1993.

2 Duncan GG, Epstein JB, Tu D El, Sayed S, Bezjak A, Ottaway $\mathrm{J}$ and Pate J; National Cancer Institute of Canada Clinical Trials Group: Quality of life, mucositis, and xerostomia from radiotherapy for head and neck cancers: a report from the NCIC CTG HN2 randomized trial of an antimicrobial lozenge to prevent mucositis. Head Neck 27: 421-428, 2005.

3 Sonis AL and Sonis ST: Oral complications of cancer therapy in pediatric patients. J Pedod 3: 12-16, 1979.

4 Sonis ST, Oster G, Fuchs H, Bellm L, Bradford WZ, Edelsberg J Hayden V, Eilers J, Epstein JB, LeVeque FG, Miller C, Peterson DE, Schubert MM, Spijkervet FK and Horowitz M: Oral mucositis and the clinical and economic outcomes of hematopoietic stem-cell transplantation. J Clin Oncol 19: 2201-2205, 2001.

5 Woo SB, Sonis ST, Monopoli MM and Sonis AL: A longitudinal study of oral ulcerative mucositis in bone marrow transplant recipients. Cancer 72: 1612-1617, 1993.

6 Cheng KK, Lee V, Li CH, Yuen HL and Epstein JB: Oral mucositis in pediatric and adolescent patients undergoing chemotherapy: the impact of symptoms on quality of life. Support Care Cancer 20: 2335-2342, 2012.

7 Spielberger R, Stiff P, Bensinger W, Gentile T, Weisdorf D, Kewalramani $T$, Shea $T$, Yanovich $S$, Hansen $K$, Noga $S$, McCarty J, LeMaistre CF, Sung EC, Blazar BR, Elhardt D, Chen
MG and Emmanouilides C: Palifermin for oral mucositis after intensive therapy for hematologic cancers $\mathrm{N}$ Engl J Med 351: 2590-2598, 2001.

8 Stiff PJ, Emmanouilides C, Bensinger WI, Gentile T, Blazar B, Shea TC, Lu J, Isitt J, Cesano A and Spielberger R: Palifermin reduces patient-reported mouth and throat soreness and improves patient functioning in the hematopoietic stem-cell transplantation setting. J Clin Oncol 24: 5186-5193, 2006.

9 Sung L, Robinson P, Treister N, Baggott T, Gibson P, Tissing W, Wiernikowski J, Brinklow J and Dupuis LL: Guideline for the prevention of oral and oropharyngeal mucositis in children receiving treatment for cancer or undergoing haematopoietic stem cell transplantation. BMJ Support Palliat Care 7: 7-16, 2017.

10 Watanabe T, Ishihara M, Matsuura K, Mizuta K and Itoh Y: Polaprezinc prevents oral mucositis associated with radiochemotherapy in patients with head and neck cancer. Int $\mathbf{J}$ Cancer 127: 1984-1990, 2010.

11 Hayashi H, Kobayashi R, Suzuki A, Ishihara M, Nakamura N, Kitagawa J, Kanemura N, Kasahara S, Kitaichi K, Hara T, Tsurumi H, Moriwaki H and Itoh Y: Polaprezinc prevents oral mucositis in patients treated with high dose chemotherapy followed by hematopoietic stem cell transplantation. Anticancer Res 34: 7271-7277, 2014.

12 Suzuki A, Kobayashi R, Shakui T, Kubota Y, Fukita M, Kuze B, Aoki M, Sugiyama T, Mizuta K and Itoh Y: Effect of polaprezinc on oral mucositis, irradiation period, and time to discharge in patients with head and neck cancer. Head Neck 38: 1387-1392, 2016.

13 World Health Organization: World Health Organization Handbook for reporting results of cancer treatment. Geneva: World Health Organization 48: 15-21, 1979.

14 Krebs NF: Update on zinc deficiency and excess in clinical pediatric practice. Ann Nutr Metab 62: 19-29, 2013.

15 Barceloux DG: Zinc. J Toxicol Clin Toxicol 37: 279-292, 1999.

16 Leitzmann MF, Stampfer MJ, Wu K, Colditz GA, Willett WC and Giovannucci EL: Zinc supplement use and risk of prostate cancer. J Natl Cancer Inst 95: 1004-1007, 2003.

17 Gallus S, Foschi R, Negri E, Talamini R, Franceschi S, Montella M, Ramazzotti V, Tavani A, Dal Maso L and La Vecchia C: Dietary zinc and prostate cancer risk: a case-control study from Italy. Eur Urol 52: 1052-1056, 2007.

18 Kristal AR, Arnold KB, Neuhouser ML, Goodman P, Platz EA, Albanes D and Thompson IM: Diet, supplement use, and prostate cancer risk: results from the prostate cancer prevention trial. Am J Epidemiol 172: 566-577, 2010.

19 Meyer F, Galan P, Douville P, Bairati I, Kegle P, Bertrais S, Estaquio $\mathrm{C}$ and Hercberg $\mathrm{S}$ : Antioxidant vitamin and mineral supplementation and prostate cancer prevention in the SU.VI.MAX trial. Int J Cancer 116: 182-186, 2005.

20 Park SY, Wilkens LR, Morris JS, Henderson BE and Kolonel LN: Serum zinc and prostate cancer risk in a nested case-control study: The multiethnic cohort. Prostate 73: 261-266, 2013.

21 Mahmoud AM, Al-Alem U, Dabbous F, Ali MM, Batai K, Shah $\mathrm{E}$ and Kittles RA: Zinc intake and risk of prostate cancer: casecontrol study and meta-analysis. PLoS ONE 11: e0165956, 2016.

22 Hayashi H, Kobayashi R, Suzuki A, Yamada Y, Ishida M, Shakui T, Kitagawa J, Hayashi H, Sugiyama T, Takeuchi H, Tsurumi H and Itoh Y: Preparation and clinical evaluation of a novel lozenge containing polaprezinc, a zinc-L-carnosine, for prevention of oral mucositis in patients with hematological cancer who received high-dose chemotherapy. Med Oncol 33: 91, 2016. 
23 Lalla RV, Bowen J, Barasch A, Elting L, Epstein J, Keefe DM, McGuire DB, Migliorati C, Nicolatou-Galitis O, Peterson DE, Raber-Durlacher JE, Sonis ST andElad S: Mucositis Guidelines Leadership Group of the Multinational Association of Supportive Care in Cancer and International Society of Oral Oncology (MASCC/ISOO). MASCC/ISOO clinical practice guidelines for the management of mucositis secondary to cancer therapy. Cancer 120: 1453-1461, 2014.

24 Naito Y, Yoshikawa T, Yagi N, Matsuyama K, Yoshida N, Seto $\mathrm{K}$ and Yoneta $\mathrm{T}$ : Effects of polaprezinc on lipid peroxidation, neutrophil accumulation, and TNF-alpha expression in rats with aspirin-induced gastric mucosal injury. Dig Dis Sci 46: 845-851, 2001

25 Shimada T, Watanabe N, Ohtsuka Y, Endoh M, Kojima K, Hiraishi $\mathrm{H}$ and Terano A: Polaprezinc down-regulates proinflammatory cytokine-induced nuclear factor-kappaB activiation and interleukin- 8 expression in gastric epithelial cells . J Phamacol Exp Ther 291: 345-352, 1999.

26 Ueda K, Ueyama T, Oka M, Ito T, Tsuruo Y and Ichinose M: Polaprezinc (Zinc L-carnosine) is a potent inducer of anti-oxidative stress enzyme, heme oxygenase (HO)-1 - a new mechanism of gastric mucosal protection. J Phamcol Sci 110: 285-294, 2009.

27 Hiraishi H, Sasai T, Oinuma T, Shimada T, Sugaya H and Terano A: Polaprezinc protects gastric mucosal cells from noxious agents through antioxidant properties in vitro. Aliment Pharmacol Ther 13: 261-269, 1999.

28 Vitale KM, Violago L, Cofnas P, Bishop J, Jin Z, Bhatia M, Kung AL, George D, Garvin J and Satwani P: Impact of palifermin on incidence of oral mucositis and healthcare utilization in children undergoing autologous hematopoietic stem cell transplantation for malignant diseases. Pediatr Transplant 18: 211-216, 2014.

29 Czyzewski K, Debski R, Krenska A, Wysocki M and Styczynski $\mathrm{J}$ : Palifermin in children undergoing autologous stem cell transplantation: a matched-pair analysis. Anticancer Res 34: 7379-7382, 2014.

30 Lucchese A, Matarese G, Ghislanzoni LH, Gastaldi G, Manuelli $\mathrm{M}$ and Gherlone E: Efficacy and effects of palifermin for the treatment of oral mucositis in patients affected by acute lymphoblastic leukemia. Leuk Lymphoma 57: 820-827, 2016.

31 Lauritano D, Petruzzi M, Di Stasio D and Lucchese A: Clinical effectiveness of palifermin in prevention and treatment of oral mucositis in children with acute lymphoblastic leukaemia: a case-control study. Int J Oral Sci 6: 27-30, 2014.

32 Ladenstein R, Valteau-Couanet D, Brock P, Yaniv I, Castel V, Laureys G, Malis J, Papadakis V, Lacerda A, Ruud E, Kogner P, Garami M, Balwierz W, Schroeder H, Beck-Popovic M, Schreier G, Machin D, Pötschger U and Pearson A: Randomized trial of prophylactic granulocyte colony-stimulating factor during rapid COJEC induction in pediatric patients with high-risk neuroblastoma: the European HR-NBL1/SIOPEN study. J Clin Oncol 28: 3516-3524, 2010.
33 Lehrnbecher T, Zimmermann M, Reinhardt D, Dworzak M, Stary J and Creutzig U: Prophylactic human granulocyte colonystimulating factor after induction therapy in pediatric acute myeloid leukemia. Blood 109: 936-943, 2007.

34 Michel G, Landman-Parker J, Auclerc MF, Mathey C, Leblanc T, Legall E, Bordigoni P, Lamagnere JP, Demeocq F, Perel Y, Auvrignon A, Berthou C, Bauduer F, Pautard B, Schneider P, Schaison G, Leverger $G$ and Baruchel A: Use of recombinant human granulocyte colony-stimulating factor to increase chemotherapy dose-intensity: a randomized trial in very highrisk childhood acute lymphoblastic leukemia. J Clin Oncol 18 : 1517-1524, 2000.

35 Sung L, Tomlinson GA, Greenberg ML, Koren G, Judd P, Ota S and Feldman BM: Serial controlled N-of-1 trials of topical vitamin $\mathrm{E}$ as prophylaxis for chemotherapy-induced oral mucositis in pediatric patients. Eur J Cancer 43: 1269-1275, 2007.

36 Shenep JL, Kalwinsky DK, Hutson PR, George SL, Dodge RK, Blankenship KR and Thornton D: Efficacy of oral sucralfate suspension in prevention and treatment of chemotherapy-induced mucositis. J Pediatr 113: 758-763, 1988.

37 de Koning BA, Philipsen-Geerling B, Hoijer M, Hählen K, Büller HA and Pieters R: Protection against chemotherapy induced mucositis by TGF-beta(2) in childhood cancer patients: results from a randomized cross-over study. Pediatr Blood Cancer 48: 532-539, 2007.

38 Raether D, Walker PO, Bostrum B and Weisdorf D: Effectiveness of oral chlorhexidine for reducing stomatitis in a pediatric bone marrow transplant population. Pediatr Dent 11: 37-42, 1989.

39 Levine JE, Blazar BR, DeFor T, Ferrara JL and Weisdorf DJ: Longterm follow-up of a phase I/II randomized, placebo-controlled trial of palifermin to prevent graft-versus-host disease (GVHD) after related donor allogeneic hematopoietic cell transplantation (HCT). Biol Blood Marrow Transplant 14: 1017-1021, 2008.

40 Morris J, Rudebeck M, Neudorf S, Moore T, Duerst R, Shah AJ, Graham M, Aquino V, Morris C and Olsson B: Safety, pharmacokinetics, and efficacy of palifermin in children and adolescents with acute leukemias undergoing myeloablative therapy and allogeneic hematopoietic stem cell transplantation: A pediatric blood and marrow transplant consortium trial. Biol Blood Marrow Transplant 22: 1247-1256, 2016.
Received May 21, 2018

Revised June 14, 2018

Accepted June 15, 2018 